\title{
American
}

Folklore Society

Keeping Folklorists Connected

Character Divination and Kinetic Sculpture in the Central Italian Passeggiata (Ritual Promenade): Interpretive Frameworks and Expressive Practices from a Body-Centered Perspective

Author(s): Giovanna P. Del Negro and Harris M. Berger

Source: The Journal of American Folklore, Vol. 114, No. 451 (Winter, 2001), pp. 5-19

Published by: American Folklore Society

Stable URL: http://www.jstor.org/stable/3592375

Accessed: 29/05/2014 15:40

Your use of the JSTOR archive indicates your acceptance of the Terms \& Conditions of Use, available at http://www.jstor.org/page/info/about/policies/terms.jsp

JSTOR is a not-for-profit service that helps scholars, researchers, and students discover, use, and build upon a wide range of content in a trusted digital archive. We use information technology and tools to increase productivity and facilitate new forms of scholarship. For more information about JSTOR, please contact support@ jstor.org. 


\section{Character Divination and Kinetic Sculpture in the Central Italian Passeggiata (Ritual Promenade): Interpretive Frameworks and Expressive Practices from a Body-Centered Perspective}

This article explores the interplay of bodily practices and interpretive frameworks in folklore performance. A case study of the Italian passeggiata (ritual promenade), the essay shows how culturally specific beliefs about the relationship between character, sociability, and the body inform expressive behavior and its interpretation. Ideas from practice theory and performance studies illuminate the unique conditions under which individual bodily performances may come together to constitute complex representations of larger collectivities.

THE GOAL OF THIS ARTICLE IS TO EXPLORE the various ways in which the body emerges in social experience and to examine the role of bodily practices in cultural performance. As a case study in the ethnography of the body, we will focus on the central Italian hilltop village of Sasso. Nowhere in Sassani life are bodily practices more visually striking or important for the establishment of meaning than in the town's passeggiata (ritual promenade). As a spectator sport, the promenade is a vehicle for people watching and for boisterous public displays; by turns quiet pastime and political theater, the promenade is the place Sassani go to see and be seen. But more than this, the passeggiata is an arena in which the townsfolk employ the body to reflect on, debate, and enact their visions of Sassani society. Here, individual performances are intended and interpreted as part of a collective social pursuit, and an analysis of this event can shed new light on key problems in the analysis of expressive culture. In the first section, we will show how Sassani use bodily metaphors to mentally organize the physical space in which the passeggiata is performed, the town's piazza (downtown area), and to make sense of the various practices that occur there. The second section will explore how Sassani interpret others' bodily presentation of self in the passeggiata and unearth the complex ideology of "bodily divination" that undergirds these interpretive practices. In the last section, we will consider the passeggiata as a kinetic sculpture of village society and

Giovanna P. Del Negro is Assistant Professor in the Department of English at Texas AEM University Harris M. Berger is Assistant Professor of Music in the Department of Performance Studies at Texas A\&M University

Journal of American Folklore 114(451):5-19. Copyright (C) 2001, American Folklore Society. 
examine how the townsfolk physically and symbolically stake out a place for themselves in Sasso's collective self-representation.

This study is animated by our ongoing interest in the relationships between Erving Goffman's analysis of face-to-face social interaction (1959, 1969), Richard Bauman's semiotics of performance $(1977,1986,1989)$, and the notion of embodied consciousness articulated in the philosophy of Maurice Merleau-Ponty (1989). Through the ethnography of the Sassani promenade we hope to problematize the body and suggest a range of ways that it may emerge in social life. By focusing on the relationship between the body and the social order, we seek to show how categories of abstract thought are constituted through concrete practices and how profound social concerns inform even the most mundane bodily acts. In so doing, we seek to relate folklore's long-standing concern with the dynamics of expressive behavior to the general dialectics of social structure and agency suggested by practice theorists such as Anthony Giddens (1979, 1984, 1993).

\section{Sasso and the Passeggiata}

The hilltop village of Sasso is located in the Abruzzo region of central Italy. Across the Italian peninsula from Rome, it is half an hour away from the Adriatic Sea and has a population of approximately 3,000 people. The town is relatively affluent compared with the smaller villages nearby, and most residents work in the factories of Sasso's industrial zone, an area that has seen strong growth in the last 20 years due to a combination of tax incentives, cheap labor, and the industry connections of local officials. Also present in the village is a small group of artisans and self-employed entrepreneurs. About $50 \%$ of the full-time wage earners own small plots of land in the surrounding countryside, and farming is a common weekend or holiday activity that contributes to the family larder.

In popular memory, Sasso is often viewed as a cosmopolitan village with close affinities to the nearby coastal centers. The townsfolk affectionately call it "la piccola Parigi dell' Abruzzo" (the little Paris of the Abruzzo) and point to its attractive thoroughfare and well-known passeggiata as a sign of civilita (civility). While the word passeggiata literally means "promenade" and specifically refers to the period of piazza strolling between 5:30 and 8 o'clock in the evening, Sassani often use the term to refer to any kind of leisure or play. The weekday passeggiata punctuates the end of the workday and routinely draws people into the bosom of the community to share moments of sociability before retiring for the evening. The Sunday promenade is dominated by family groups and is shorter in duration, usually lasting only one to two hours. The spring's temperate weather brings the less mobile and the elderly onto stoops, terraces, and balconies to watch the event, while the summer months are the passeggiata's high season. Here, locals, immigrants, returning students, and those vacationing in Sasso for the summer add to the seasonal excitement and anticipation surrounding the summer feste (celebrations). 


\section{The Body as Metaphor: Conceptualizing the Piazza in Everyday Language}

Sassani routinely use bodily metaphors to describe the town's center. Such linguistic markers delimit the boundaries for strolling and establish an interpretive framework for conducting interaction in the social space of the piazza. To understand how the mental image of the body maps the microcosm of human capacities to the macrocosm of public space, a more detailed discussion of the geographical and architectural features of the village center are required.

Sasso's main thoroughfare, il corso Vittorio Emanuele (Vittorio Emanuele boulevard), terminates in a town square and a fountain, behind which lie the local church and a secluded park. A medieval town with large fortress walls, today's Sasso is the product of hundreds of years of construction and reconstruction. Originally the center of town was located in what is now called Sasso's "old quarter," but the landslides of the 1880s destroyed many homes, and subsequent development shifted the center outward in the direction of the current piazza. The villa, a small, carefully landscaped park behind the church, was built in the early 1900s, and the geometrically shaped topiary in its adjacent garden appear to be inspired by the English natural style of that period. In the 1960s, the old San Bernardino church was torn down and rebuilt, along with the piazza's current octagonal fountain. Unlike the narrow streets found elsewhere in Sasso, the main corso is broad and open, recalling the urban designs of 19th-century European boulevards. Near the fountain, a bank, a gas pump, and the balconies of private homes overlook one side of il corso; across the street, a Madonna sits in a small V-shaped park. Moving further from the church, various boutiques, cafes, bars, newspaper stands, and fruit shops line the wide sidewalks along the boulevard; at the far end is found the police station and city hall. While the term piazza literally means "town square," it is usually used in Sasso to refer to the entire area from the park to the police station. Tree-lined and slightly concave, il corso pulls strollers from the piazza's extremities to its center. Pausing in their countless vasche (laps) across that boulevard, the street's slight depression allows strollers to experience the piazza as a cinematic whole.

The bodily metaphors that structure the participant's view of the piazza are binary. The area including the church and the villa is referred to as il capo (dialect for "the head"), while the lower half of the piazza and the area beyond it are called quarta da peda (dialect for "side by the feet"). One function of these metaphors is to define the physical boundaries of the event. In Sasso, everybody knows that one's passeggiata terminates at the end of the "feet," a specific point in space just short of the city hall, and to go beyond that point is to be outside the realm of public life. Here the metaphors provide Sassani with invisible maps that tell people where to stop and reverse the direction of their walking. When people reach the boundary point, they turn around in a seamless, choreographed manner and resume their vasche down the thoroughfare. Locals humorously call this the changing of the guard, and in her fieldwork, Del Negro discovered the turning point by unintentionally breaking the rules and going past the acceptable boundary.

But more than simply marking the physical boundary of the event, these bodily metaphors serve as ways of endowing different parts of the piazza with specific meanings and values. As in all comparative figures of speech, the metaphor's conjunction of 
image with image comments on the two halves of the device in a reciprocal and selective fashion, ascribing specific meanings to each term and leaving latent other meanings that they might possess. For example, the human head could be connected with a wide range of associations: It is the site of reflective thought, but also of speech, ingestion, breath, vision, hearing, taste, and an array of other processes. Associating this part of the anatomy with a place noted for its stunning views, its proximity to the church, and its isolation from street noises, the Sassani imagination envisions the head as an organ, not of talk or taste, but of quiet contemplation. By the same token, the metaphor depicts the villa as a kind of head-a high and exalted place, a place of reflection (rather than a place of talking or eating). These meanings are reinforced and adumbrated by their relationship with the street/feet metaphor. The feet, of course, can also symbolize an open-ended range of meanings: dirt, groundedness, sensuality, work, progress, movement. Opposed to the pastoral and private capo and paired with a zone of bars, cafes, and boutiques, il corso takes on a set of meanings complementary to those of the villa. It becomes a lower region, a place of sensuality, a place where the social machinations of commerce and politics, not pastoral beauty or reflective thought, hold sway. Such pairings symbolically equate the upper regions of social life with the divinely inspired forces of the human spirit, while the lower regions are relegated to biologically driven impulses and desires. If cleanliness is next to Godliness in Sasso, then vertical upwardness and the head are the center of reflection and the point closest to the celestial heavens. Conversely, "the side by the feet" is worldly, in the fullest sense of the word-a place that is both below God's heavens and a place where the pleasures of the world and human society may be found.

Such ideas inform, and are reinforced by, the activities that occur on the passeggiata. In practice, il capo is reserved for quiet conversation and reflective meditation. Strollers go there to admire the panoramic vista of the nearby villages and the lush hilltop vegetation so characteristic of the Abruzesse landscape. In this "head" region, Sassani customarily seek out moments of peaceful introspection and respite from the hustle and bustle of modern life. This is where people come to think and focus upon things of the mind, away from the distractions of the world; it is the mental and spiritual center of the body politic. No one spectates in the villa, and the presentation of self is subdued there. Bodily postures are more relaxed, and if personal conversation is to be had during the promenade, it will take place on a quiet bench in the villa, not on il corso. As people leave the villa, however, attention to social dynamics is heightened and the presentation of self becomes more actively performative. Entering the square, subtle changes in physical bearing occur and the Sassani's posture becomes more upright and erect. Strollers make a special effort to observe the etiquettes of greeting, and conversation is more carefully controlled. Where the participants had focused on intimate thoughts and natural beauty, they now attend to the sartorial displays of others and the pleasures, and pitfalls, of Sasso's social life. Thick with voices, smells, and visual stimuli, the activities of il corso revolve around interaction, around seeing and being seen. In the area above, nature and reflective thought reign supreme, while the area below is clearly devoted to the secular activities of commerce and what, in other contexts, Kathy Peiss has called "cheap amusements" (1986). In sum, by marking the boundary 
conditions of this sphere of interaction and establishing ideas of proper conduct, bodily metaphors serve as kind of ordering principle for the passeggiata.

\section{The Body as Symptom: Uncovering Character in Bodily Divination}

The body is, of course, more than a set of metaphors, and interpreting others' bodily presentation of self is a key part of the Sassani passeggiata. While the reading of an other's body language is certainly a universal human activity, each culture makes the act of interpretation meaningful by reference to local ideas about the body, the character, and the self. In Sasso, these interpretations are predicated on the belief that each individual has an essential character, a moral nature that is both stable and innate. Unearthing that character, however, is not an easy task. On the one hand, Sassani see the body as an oracle of moral integrity; on the other hand, they recognize that actors chronically manipulate the images they project. Constantly aware of the tension between these ideas, Sassani seek to pierce the veil of the other's "impression management" (Goffman 1959) and glimpse the ethical essence that they believe lurks within. This faith in a stable moral character obscured by artifice but ultimately discoverable through cunning observation forms an interpretative framework that we will refer to as bodily divination. Piecing together disparate clues and hunches, Sassani bring the skill of an experienced detective to bear on the problem of discerning the character of the other participants.

Bodily divination in Sasso involves attention to a wide variety of clues including, but not limited to, deportment, costume, gait, gaze, facial expressions, and proxemics. How are we to understand this varied assortment of signs and reconcile them with the primacy of the body? Erving Goffman once observed that the body "exudes expressions" (1969:5). This is true, but when operationalizing this notion in fieldwork, the definition of the body immediately becomes problematic. The body does exude expression, but to understand embodied social practices in fieldwork, we must recognize that those expressions are exuded through a number of dimensions and linkages.

Costume, for example, is a dimension of the body. While the suit that one wears is obviously not a part of one's body, it is absurd to speak of clothing without conceptualizing it as tied in action to the body to which it is literally tailored. Deportment is another dimension of bodily practice; by deportment we mean the various postures in which the arms, neck, back, hands, and head are held. In the abstract, one can deport oneself any way one likes. In the concrete, however, all but the most skilled dancer find the control of deportment to be a different thing from simple volitional activity. For most of us, deportment is the kinetic grounding from which all other bodily practices emerge, the default position from which intentional activity is launched. By the same token, however, the muscular tensions that make up deportment are not as far from conscious manipulation as processes like digestion or blood circulation. For this reason deportment exists at the meeting place of the body as physical object and the body as a medium of intentional activity. And while largely automatic functions like breathing and intentional functions like gross gestures of the hands and face may represent the poles of the dialectic of the body as object and the body subject, contemporary research by writers as different as George Lakoff (1987) and Maurice Merleau-Ponty 
(1989) suggests that these two modalities of bodily practice can never fully be divorced. In the concrete interpretive practices of the passeggiata, Sassani's readings of others in the piazza entwines costume, deportment, gesture, and other dimensions of the body in an inextricable whole, and it is this ensemble that is understood as the symptom of an individual's underlying character. Never fully controlled but always potentially open to manipulation, the expressions of the body are dynamic and interactive. It is that social and responding body that Sassani read as an oracle of character.

In the bustling interpretive marketplace of the piazza, the body and its linkages are seen as a potential source of insights into the essential nature of others in the promenade. Erect posture, for example, is often equated in Sasso with feminine virtue and self-possession. Here, it is believed that young women should take their passéggio (walk) at a moderate pace and limit their direct eye contact with others in the piazza; such a style is thought to indicate the proper balance of self-assuredness, sexual propriety, and sociability. While styles of walking are sometimes seen to express an individual's status in the community, they are more often interpreted as a reflection of character. In this context, a pleasing countenance not only reveals an affable mood, but an interior goodness that transcends manners or ephemeral emotional states. Similarly, the elegantly dressed woman can, by virtue of her appearance and demeanor, radiate social refinement; more important, her bodily deportment will be seen to reveal trustworthiness. To be retto e corretto (literally, "upright and correct") in Sasso is to be an upstanding and praiseworthy person, one whose physical bearing displays moral rectitude.

In order to probe the dynamics of these interpretive processes, Del Negro videotaped the passeggiata and conducted feedback interviews on the video data with selected participants. This technique was useful in revealing to what spectators attend in the piazza and provided an entrance into the ideas that undergird bodily divination. At the beginning of the feedback interviews, almost everyone watched with curiosity and interest. While some people remarked at how beautiful the town looked, others made disparaging comments about their townsfolk's penchant for self-display. In the first few minutes of video viewing, Sassani townsfolk usually tried to recognize people in the crowd, identifying them by their clan names and their relationships to others in the community. In the midst of the banter, humorous quips, and sarcasm, participants slowly began to focus their attention on individuals and to impute specific meanings to their behavior. More than off-the-cuff remarks about particular styles of presentation, these comments were snapshot assessments of character. Through a series of rapid mental observations, informants picked out particular features of other's bodily performances (posture, gait, gaze) as telltale signs of intrinsic qualities. By probing beneath what they viewed as the camouflage of artifice, Sassani sought the moral dimensions of character.

Throughout the interviews, deportment emerged as one of the most important signs of internal qualities. A slumping posture was seen as indicative of both a disinterest in the event and a loutish nature, while a rigid back and neck suggest artificiality and an inflated self-image. Here, posture betrays character despite the actor's most studious efforts to control her or his self-presentation. This point became enormously clear when Maria, a lifelong Sassani, described the posture and gait of a woman on the tape as ridiculously 
forced and indicative of arrogance: "Look at her, tutto impostata [dialect: "all stiff and haughty"]. She is arrogant and superior. She doesn't greet anyone in the street." Silvana, another townswoman present that day, added, "She [the woman in the tape] is nothing more than a stupid woman who has come into some money. Her grandmother was cheap and greedy and only had one dress to wear. Now she walks impostata and with her nose in the air." Analyzing Sassani responses in retrospect, we suggest that it is not surprising that deportment would be so crucial for those committed to an interpretive framework such as bodily divination. By its very nature, a person's deportment is an indicator of his or her energy level and attentiveness to the immediate environment; unlike other elements of behavior, however, deportment is difficult to maintain under volitional control. Only the finest stroller can consistently support an upright but relaxed posture across a single passeggiata or a full season of promenading. Like an actor affecting an unfamiliar dialect in a role, the passeggiata participant faces endless opportunities for slouching, stiffness, or other kinesic gaffes. An unusually upright posture at the end of a long, tiring evening, a neck tight with tension during a seemingly relaxed conversation, a casual posture in a formal interaction-each of these could indicate deception to the bodily diviner. For those who seek out ineffectively censored expressions, meaningful but difficult to control dimensions of bodily behavior-like deportment-are an ideal source of information. While no Sassani explicitly stated that they attended to deportment for the reasons we have elaborated, the scrutiny of posture was a key part of local interpretive practice. Suggestive of mental states and situated at the far edge of conscious control, deportment is a weak spot in the actor's impression management and excellent grist for the Sassani's interpretive mill.

In some instances, only a brief glance was necessary to provoke pronouncements about an individual's character. During one of Del Negro's daily walks, a young female friend of the fieldworker's remarked about a passing man, "Look at his eyes, he's so avaristic and greedy." This judgment was but a fleeting observation in the running commentary that makes up the passeggiata, but it indicates a crucial feature of the event. In this vision-centered activity, ongoing, reflective interpretations of character are a constant element of passeggiata experience. A continuous flow of evaluations forms the texture of the passeggiata stroller's interior life. In many ways, fast-moving gestures and furtive glances are the stuff of which the promenade is made, and, intentionally or unintentionally, individuals in this milieu continuously evoke an abundance of moods, meanings, and responses. Through this blizzard of ephemeral information Sassani seek out those expressions that they believe are external manifestations of internal predilections. None of this is to say that there are not frequent disagreements over the veracity of individual interpretations. But while the character judgements can be highly idiosyncratic, the underlying commitment to bodily divination is widely shared among Sassani.

The reading of character is so basic to Sassani life that the divinatory interpretive framework itself is brought into different discourses and given different valences. Describing their passeggiata experiences, some Sassani seemed to represent particularly effective interpretations of character as moments of lucidity, flashes of second sight otherwise reserved for saints or those with paranormal powers. Taken in this light, bodily divination takes on an almost mystical quality, and the connections between 
contemporary interpretive practices and long-standing traditions in Italian esoteric thought is a provocative one. Discussing ideas about the relationship between the face and the soul in medieval Italy, Patrizia Magli describes a belief in a "cosmic system of correspondence" that highlights the relationship between "microcosm and macrocosm" (1989:367). In this cultural "taxonomy of [quasi-]permanent moral characteristics," as Magli puts it, "the world appears in a symptomatic way, wherein things are signs of the other things" (Magli 1989:103). But a discourse of the supernatural is not the only one into which bodily divination might fit. Just as medieval alchemy is often represented as a kind of proto-science, contemporary Sassani often depict their assessment of other's moral essence as a scientific and empirical pursuit. Marshaling evidence and organizing arguments, Sassani often describe their characterological inferences as hypotheses and seek evidence to bolster their conclusions. Viewed in this way, the IQ test is to intelligence as Sassani bodily divination is to human character. Most often, however, Sassani represent bodily divination as a battle of cunning and will. In fact, the conflict between the stroller's presentation of self and theinterpreter's capacity for penetrating observation provides the passeggiata with one of its central tensions. Paradoxically, the very emphasis on appearance and polite decorum in the piazza leads Sassani to greater speculations about the deceptions that lie beneath the patina of social niceties. Participants frequently expressed the belief that civility is a sham, a game of trickery and cunning that demands great powers of discernment on the part of the interpreter. The social observer therefore attempts to probe the deeper meanings that underlie bodily expressions by carefully studying and analyzing the interactions that take place in the piazza. By mentally peeling away the levels of social conditioning and the carefully tailored gestures, Sassani hope to penetrate the cultural defense mechanisms that prevent the uncensored flow of information between people. These second and third order readings are intended to reveal the underlying forces that impel human beings to act in certain ways.

The seriousness of bodily divination is most evident when viewed in the context of recent Italian politics. Del Negro's fieldwork occurred during a period of political turmoil in Italy. Referred to as tangentopoli (literally, "bribesville"), the series of scandals that rocked Rome's political elites had reverberations in Sasso. A variety of local officials had positions in the national government, and charges of clientalism and nepotism in the disbursement of development funds were leveled at some of the town's most powerful figures. During one two-week period, this village of 3,000 saw over 20 of its elite placed under house arrest. In the politics of small-town cronyism, one's economic fortunes depend upon one's ability to distinguish the trustworthy from the duplicitous, and, rationally or irrationally, Sassani view bodily divination in the passeggiata as a key survival skill. Here, human behavior is likened to Plato's cave, where mortals only see the reflections of more profound forces at play.

While bodily metaphors suggest the piazza as a coherent social space and map relationships between the microcosm of the human body and the macrocosm of the piazza, the interpretive practices of bodily divination constitute the body as a coherent set of signs and map relationships between the macrocosm of the body and the microcosm of the character. Marking boundary conditions and instituting relationships between 
classes of phenomena, the body acts as a kind of fundamental ordering principle and helps to establish the passeggiata as a coherent domain of experience.

None of this is to say that bodily divination is the only activity that occurs on the piazza. While serious character analysis is an almost obligatory part of the promenade, it does not always occupy center stage. Sassani are also concerned with the aesthetic components of expressive behavior and frequently relegate their theories of human character to the margins of their awareness. In those moments, the ludic is foregrounded and observers evaluate townsfolk on their skillful execution of the various forms of dress and behavior. Where interpretations in the mode of bodily divination are characterized by a concern with character and local political drama, aesthetically oriented interpretations treat the passeggiata as carnival and the presentation of self as escapist theater. In the former mode, participants treat the other participants' presentation of self as a kind of Umberto Eco novel, an elaborate text and a mystery to be decoded; in the latter mode, the other's bodily performance is more like a piece of romance fiction with gratifyingly formulaic endings. In any given passeggiata, the participant's experience shifts back and forth across this continuum, foregrounding and backgrounding these interpretive modes as they selectively respond to the myriad of messages that occur in the piazza.

\section{The Body as Medium: Images of Society in Passeggiata Performance}

When people go out for the passeggiata, they are engaged in a performance. Through proxemics, kinesics, fashion, and speech each individual uses his/her body as a surface for depicting social meanings. In a simple and direct sense, this is the performer side of the performer/audience interaction described in the previous section. What we wish to show here, however, is how Sassani use their bodies to create a representation-a kind of moving tableau or kinetic sculpture-of Sassani society. In passeggiata performance, the various constituencies of the village literally stake out a place for themselves in the physical space of the piazza and metaphorically stake out a place for themselves in the social space of village society. In so doing, each lays claim to the traditional Sassani virtues of sociability, civility, and cosmopolitanism, and addresses broader questions of identity and power.

It is not hard to understand how the ethnographer would interpret the passeggiata as a kind of kinetic sculpture of village society. Standing on a balcony with video camera in hand, Del Negro takes in the event as a whole and sees an image of local social life: power relations, generational conflicts, issues of gender and class, and the collective desires for sociability all play themselves out before the scholar's gaze. But to say that the passeggiata appears to the ethnographer as a representation of Sassani society is a much weaker statement than the one we wish to make here. On the contrary, we seek to show how Sassani themselves see the passeggiata as an image of the local society and their performance as a contribution to this improvisatory social theater.

This, too, might be understood in a straightforward sense. Sassani see an empty piazza as an image of rural boredom and a bustling piazza as a sign of village vitality. Townsfolk often speak of the cultural imperative to make lo struscio. Literally "the rub," lo struscio refers to any kind of pleasant and flowing social interaction and the sense of warmth 
and sociability that such experiences engender. In numerous interviews, Sassani depicted the pursuit of lo struscio as both a biological need and a social responsibility. The primary site of lo struscio in Sasso is the passeggiata. It invites citizens from all backgrounds to leisurely congregate in the public square and participate in the civilizing practice of artful conversation. Above all else, it is a place where people come to be in close physical proximity with others, huddling in groups and walking arm in arm to reaffirm their interdependence. To stand by yourself during this collective display of public allegiance is to forfeit the right to be a Sassani in the fullest sense of the term. The importance of sociability in passeggiata performance is most clearly illustrated by the negative example of Sasso's lone walker. This gentleman marches up and down il corso with an almost mechanical gait, lacking the fluidity and spontaneity that most strollers display. He walks self-consciously and without style; his demeanor suggests heightened purpose - a compulsion. He seldom greets people, and other Sassani uniformly avert their gaze from him. In his frenetic, antisocial passeggeo the lone walker is, in the local view, the antithesis of the spirit of the Sassani passeggiata.

But the passéggio is more than just an image of village sociability or a uniform collective identity; to the Sassani themselves, the passeggiata is a performance of village life, and the stroller's body is a medium for constituting representations of the local society as a whole. The notion may at first seem to be a contradictory. There is no central planning group that coordinates the passeggiata performances. How can the individually pursued bodily activity of the strollers be understood as an intentional representation of the wider social order? Though enacted individually or in small groups, the performances of each individual stroller are viewed, by themselves and others, against the background of the event as a whole. Thus, while the individual participants use only their own body as a medium of expression, each individual understands that his or her actions will be interpreted in the context of all the other participants in the event, a context that includes representatives of almost every segment of Sassani society. Situated alongside those of all classes, ages, genders, marital statuses, and political affiliations in the town, the stroller's body is interpreted as neither an individual body nor part of a uniform group; it is intended and interpreted as a part of an organization of bodies. In short, the common awareness of a totalizing context transforms the individual body into a member of society, and individually pursued and uncoordinated passeggiata practices become representations of the society as a whole.

The clearest way to illustrate this notion is through the idea of staking one's place. Individuals on the passeggiata symbolically stake their place in society by laying claim to particular physical locations in the piazza. For example, elected officials frequently display their political power through passeggiata performance. Walking arm in arm from capo to quarta da peda, this chain of ten to twelve men occupy the whole width of the street, dominating the entire piazza in a show of power and solidarity. The men who mill near the sidewalk bars usually turn and raise their heads to watch their politicians strolling in an unbroken line. Such a display would always change the dynamics of the event. Walking in this way, the politicians have almost complete control of the street, making it difficult for other participants to pace at the rhythm at which they were accustomed, and many strollers choose the path of least resistance by walking around them. As a participant-observer, Del Negro often wondered how far down the 
thoroughfare the chain would proceed before it disbanded and regrouped again. During Del Negro's first year of fieldwork, the town's Democratic Christian (DC) mayor, a figure embroiled in corruption scandals, and his cronies were conspicuously absent from the promenade. Six months latter, the town had ousted the DC strongman and elected a leader with socialist ties. During her second field trip, Del Negro observed Sassani glance with distrust as the new mayor strolled along side members of the previous administration. In this context, the actor's use of space reflects his/her political power. By virtue of their position in the social hierarchy, Sassani politicians occupy a central place in the life of the town, and the spatial dynamics they bring to the promenade reflect this reality. The sanguine self-confidence with which the politicians dominate the piazza acts as a forceful reminder to the townsfolk of the influence the politicians exercise in village life.

If, during the promenade, political leaders conveyed their centrality in the community by commanding greater social space, Sassani widows communicated their marginality in society by operating on the sidelines of the event, frequently enjoying the proceedings from the edge of the street, the balconies, the terrace, or the stoop. In central Italian culture widows are expected to abide by the ideals of female modesty and virtue; their lives have historically been censured by religious doctrine, and their activities in the public sphere have been limited. Because of these long-standing social strictures, widows are seldom seen promenading in the center of the piazza during the peak hours of the event. While the widow Maria, for example, thought it was unsuitable for a woman in her position to stroll on il corso, she hardly ever missed an occasion to sit on her balcony and watch the proceedings. On a nice day, she would typically lean against the railing to greet and converse with passersby. As a rule, however, she only would venture off into the piazza to do her morning's shopping or practice needlework in the villa.

While the widows reaffirm and embrace their marginalized role in Sassani society by watching the passeggiata from the sideline, they also use their presence to assert the power of what we call the "marginal gaze." As the unofficial arbiters of propriety, they sit in judgment of the strollers on the street, their watchful eyes reminding those below to fare la strada diritta (follow the straight and narrow path). Though their behavior is sharply circumscribed by their age and gender, these features of their identity also afford them certain kinds of freedom and power that are out of bounds for ordinary citizens. They possess the luxury of speaking their minds and may even take liberty with the social conventions they themselves uphold. In fact, Sassani teenagers fear the reprisals of the widows and the gossip that is their traditional domain. The coercive male gaze that women's studies scholars describe in their work has its counterpart in the equally powerful female gaze of the Sassani widows. This is not to say that Sasso is a feminist paradise; in fact, the rules of decorum that the widow's gaze uphold are often restrictive to women. To deny, however, the power that the widows do possess is equally to misunderstand the situation. In the passeggiata performance, as in society, the margins are a location in a social continuum.

The physical centrality of the politicos and the marginality of the widows are obvious metaphors for their position in Sassani society, but not all staking of place in the promenade operates through spatial location and spatial metaphors. In fact, passeggiata 
participants use a wide array of expressive devices to position themselves in the event's collective representation of Sasso, and the highly prized values of civilità and cosmopolitanism play a central role here.

As we suggested above, the townsfolk refer to Sasso as the "little Paris of the Abruzzo," and notions of modernity and urbane sophistication are crucial for Sassani discourses of local identity. The commitment to these ideas is exemplified by the community's high regard for the expressive presentation of self in the public arena. This cultural imperative is perhaps nowhere more evident than in the actions of the stylishly dressed female adolescents. Provocatively sashaying up and down the street with their coterie of friends, teenage girls on the passeggiata seek to affect airs of insouciance and urbane worldliness. While expensive clothing is a desiderata for most passeggiata participants, bearing and demeanor are the crucial elements of performance, and a skilled adolescent may conjure images of sophistication and style with a simple flick of the wrist or a raising of the chin. And teens are not the only ones who seek to emulate the poses that grace the pages of Italy's fashion magazines. Parading in light colors and tailored suits, a small but growing cadre of middle-aged professional women seek to claim for their own the values of cosmopolitanism and sophistication. Backgrounding the sexuality that adolescents emphasize, their constructed presentations of perceived "sophistication" embody both traditional ideas of femininity and their achievements as career women. Such displays of sophistication yoke the broader cultural values of civility to the qualities modern feminine respectability appropriate, in the local view, to their gender and age. In imitation, some young women pattern their clothing on that of the middle-aged professionals. Within this context, teenage girls, young women, and middle-aged professionals stake a place for their identities in the larger community values of civility and urbanity.

While Sassani performances of identity can reach great heights of nuance and detail, the disruptive antics of the motorini (moped) boys are anything but subtle. A source of constant annoyance to the other strollers, the motorini boys' rambunctious performance of masculine identity is an essential part of the dynamic street culture of Sasso. With their sports jackets, designer sunglasses, and gelled hair, these late teens lean against their bikes and watch the crowd go by. Smoking, scowling, and engaging in horseplay, they occasionally try to interfere with the rhythm of the walkers' passeggeo. The revving of their motors and their boisterous, often incoherent, yells frequently provoke shouts of reprisals from passersby. On busy days, the teens' line of vision is often severely hampered by the sheer density of people in the piazza; outnumbered by pedestrians and incapable of even looking across the street to the park, the motorini boys make a grand exit, roaring through the crowd in a noisy cavalcade. Despite the motorini boys' disruptive antics, the walking hordes clearly control the street. Cowed by the dominant walkers, the adolescent males struggle to stake out their place in this public arena, withdrawing only when they are incapable of participating to their satisfaction. In many ways, their desire to assert their will in the passeggiata parallels the broader battles of the teenage years-the struggle to transform themselves from dependant children to autonomous adults.

In each of these examples, we see participants on the passeggiata using their bodies as a medium of expression to make statements about the character of Sassani social life. 
While not every act in the piazza is meant as an analytic judgement (sometimes going for a walk is just going for a walk), there is no doubt that people go into the piazza to see and be seen. Contextualized by representatives of every segment of Sassani society and oriented toward the perception of the town as a whole, bodily practices acquire the potential to be more than reflections of the individual's state of mind. Just as a figure cannot exist without a ground in visual perception, neither can an individual social role exist independently of its relationship to the other social roles. It is precisely this mutually dependant web of relationships that constitutes a social space. Because each of the individual participants knows that his/her performing body will be a figure literally viewed against the background of the piazza and metaphorically viewed against the background of the totality of Sassani social roles, individual bodily performances are intended and interpreted as constituting a representation of society as a whole. The unique systematicity of the passeggiata allows individual and spontaneous bodily practices-uncoordinated by a consciously constructed external plan-to constitute a collective and integrated representation of the broader Sassani society.

Purely structural features of the passeggiata help to bring about this state of affairs. The small scale of the village (less than 3,000 people), the high population density, and the general participation of the populace in the event guarantee that, on most nights, representatives of every strata and division of Sassani society are in attendance in the piazza. The presence of such a representative sample allows the event to come to a kind of semiotic critical mass and attain the systematicity that is so crucial to its functioning. The structural determinate of architecture also plays a role. The wide thoroughfare, deep sidewalks, omnipresent cafes, scenic villa, low balconies, bench-filled median strip, and gently sloping contour of il corso serve as the perfect arena for viewing others and making social observations. Such structural determinants, however, are necessary but not sufficient conditions for the passeggiata, and it is the creative agency and social imagination of the townsfolk that call the event into being. Each participant is a partial author, but that partial authoring is perceived and intended as constitutive of a systematic whole. By staking a place in a social totality, the participants' bodily practices are not just statements of individual values or identity. The determinants of scale and architecture enable bodily practices to become evocations-utopian, conservative, literal, radical, ironic, satiric - of Sassani society writ large.

Weaving and woven into the systematic web of the passeggiata, any individual action may take on unexpected meanings. The surprising confrontation, the unanticipated formation or disintegration of relationships, the moment of sudden social insight-all these make up the serendipity of street performance and evoke the emergent systematicity that is characteristic of the phenomena of society in general. As a result, individual bodily practices become a kind of cultural criticism and the body serves as a media of profound social expression.

\section{Conclusions: The Body, Meaning, and Social Order}

Since at least the mid-1970s, the body has become an important focus for humanistic ethnography. Like many scholars, we are interested in the role that the body plays in the construction of social meanings. One goal of this article has been to problematize 
the notion of the body and illustrate the various ways in which it emerges in experience. As Maurice Merleau-Ponty has rightly observed (1989), our embodiment is the basis for our engagement with the physical and social worlds. This basic insight is best understood not as the conclusion of a philosophical debate but as an invitation to ethnography. On a theoretical level, it is clear that the body is the ground of meaning; however, when we take the body as the focus of field research, we see that it emerges in our experience through a culturally specific range of dimensions and linkages whose endless diversity is limited only by the contingent history of a given social world. In the Sassani passeggiata, the body is present for the participants as a concept, a surface to be interpreted, and a medium of expression; it is used to make sense of the piazza, to provide entrance to character, and to constitute a representation of social life; it is represented and metaphorized, draped and comported, positioned and viewed, displayed and interpreted. If all experiences are bodily, then the body has the capacity to engage with all kinds of experiences, and one goal of this paper has simply been to suggest some of the various ways in which the body emerges in the social life of meaning.

We also wish to suggest the various ways in which Sassani use the body as a kind of ordering principle to constitute domains of experience. Sassani use metaphors to relate the body to the geography of the piazza. Sassani use a complex symptomology to relate the body to underlying features of character, and it is through collective and sometimes contested bodily practice that Sassani sculpt a kinetic representation of village society. In each instance, Sassani do not merely use the body to make meaning; rather, they use it to establish the boundary conditions and the basic structures of different spheres of experience. Embedded in everyday linguistic practice, the image of the body delimits the sphere of piazza and invests its various locations with the different valences. In bodily divination, it serves as an entrance to the domain of the character, and it is on that contested ground that a battle of obfuscation and cunning interpretation are waged. Taken with other bodies, the single body serves as the medium for representing the entire sweep of Sassani society. In all three cases, it is the body that Sassani use to establish frames of reference and convert the chaos of that which can be sensed into an ordered cosmos of experience.

By taking the body and its connections to the world as the means by which coherent domains of lived experience are constituted, we are able to understand social phenomena in terms of concrete practices. Both the transparency and the opacity of meaning, the reproduction of power relations and their resistance, the consistency and the variability of experiences within a culture, all come about because our social actions are neither the product of determined physical mechanisms nor protean ideas but, rather, bodily practices. The body is the meeting place of structure and agency, creative action and its limitation, the "interior" space of the mind and the "exterior" space of the world. It is by focusing on the bodily dimensions of meaning making, we believe, that scholarship can return even the most abstract social values and processes to the concrete reality of social life, the body subject in the quotidian world.

\section{Note}

Giovanna P. Del Negro expresses her appreciation to the Folklore Institute at Indiana University for the Richard M. Dorson Research Grant, which helped to fund part of the fieldwork on which this essay is 
based. The data for this study are based on Del Negro's 14 months of extensive participant-observation in Sasso from February 1993 through April 1994, with a second visit in May 1995. Because of the political nature of related research, the name of the town and the individual participants in the study have been changed.

\section{References Cited}

Bauman, Richard. 1977. Verbal Art as Performance. Rowley, Mass.: Newbury House Publishers. 1986. Story, Pefformance, and Event. Cambridge: Cambridge University Press.

1989. Performance. In The Intermational Encyclopedia of Performance, ed. Erik Barnouw, pp. 262-266. Oxford: Oxford University Press.

Giddens, Anthony. 1979. Central Problems in Social Theory: Action, Structure, and Contradiction in Social Analysis. Berkeley: University of California Press.

1984. The Constitution of Society: Outline of a Theory of Structuration. Berkeley: University of California Press.

1993. New Rules of Sociological Method: A Positive Critique of Interpretive Sociologies. 2nd edition. Stanford: Stanford University Press.

Goffman, Erving. 1959. The Presentation of Self in Everyday Life. New York: Doubleday. 1969. Strategic Interaction. Philadelphia: University of Pennsylvania Press.

Lakoff, George. 1987. Women, Fire, and Dangerous Things. Chicago: University of Chicago Press.

Magii, Patrizia. 1989. Face and the Soul. In Fragments for a History of the Human Body, Part II, ed. Michel Feher, Ramona Naddaff, and Nadia Tazi, pp. 86-127. New York: Urzone Press.

Merleau-Ponty, Maurice. 1989. Phenomenology of Perception. Trans. Colin Smith. London: Routledge.

Peiss, Kathy. 1986. Cheap Amusements: Working Women and Leisure in Tum-of-the-Century New York. Philadelphia: Temple University Press. 